\title{
Design, synthesis, structural characterization and cell cytotoxicity of a new derivative poly(maleic anhydride-co-vinyl acetate)/miltefosine polymer/drug conjugate
}

\author{
G. Karakus ${ }^{1 *}$, Z. Akin Polat ${ }^{2}$, M. Karahan ${ }^{3}$ \\ ${ }^{1}$ Division of Pharmaceutical Chemistry, Faculty of Pharmacy, Cumhuriyet University, Sivas, Turkey \\ ${ }^{2}$ Division of Medical Parasitology, School of Medicine, Cumhuriyet University, Sivas, Turkey \\ ${ }^{3}$ Division of Bioengineering, Faculty of Engineering and Natural Sciences, Üsküdar University, Uskudar-Istanbul, \\ Turkey
}

Received, May, 31, 2018; Accepted, January 18, 2019

\begin{abstract}
In recent years, polymeric systems are selected as biomaterials because of their desired biocompatible properties and easy design/preparation of a number of different structures with lower toxicity and good solubility. Nontoxic polymeric drug carrier, maleic anhydride-co-vinyl acetate copolymer (MAVA), was prepared via free-radical chain polymerization at $80 \pm 0.1{ }^{\circ} \mathrm{C}$. MEK (methyl ethyl ketone) and BPO (benzoyl peroxide) were used as the organic medium and radical initiator, respectively. Copolymer was conjugated with a broad-spectrum antimicrobial agent, miltefosine (MF, an oral drug in the treatment of leishmaniosis), Impavido ${ }^{\circledR}$ and Miltex ${ }^{\circledR}, 1: 1$ molar ratio of copolymer:drug for $48 \mathrm{~h}$ at $60{ }^{\circ} \mathrm{C}$ in aqueous medium in presence of $\mathrm{N}$-(3-dimethylaminopropyl)-N'-ethylcarbodiimide hydrochloride (EDAC). Fourier transform infrared (FTIR) and nuclear magnetic resonance $\left({ }^{1} \mathrm{H}\right.$ - and $\left.{ }^{31} \mathrm{P}-\mathrm{NMR}\right)$ were used to characterize the structure of the copolymer and MAVA/MF conjugate. Molecular weights were measured via size-exclusion chromatography (SEC). Results, obtained from the spectroscopic and SEC analysis, verified that conjugation was successfully carried out with good water-solubility. WST-1 cytotoxicity tests, $24 \mathrm{~h}$ by quantitative analysis, were carried out for copolymer, miltefosine, and MAVA/MF. The cytotoxicity values, by comparing with control group, were found statistically significantly different $(\mathrm{P}<0.05)$. MAVA/MF copolymer/drug couple was successfully designed with lower cytotoxicity than the free drug (MF).
\end{abstract}

Keywords: maleic anhydride-co-vinyl acetate copolymer conjugation, miltefosine, cytotoxic activity, FTIR, ${ }^{1} \mathrm{H}-\mathrm{NMR}$, ${ }^{31} \mathrm{P}-\mathrm{NMR}, \mathrm{SEC}$

\section{INTRODUCTION}

Anhydride containing polyanhydride copolymers have been commonly applied, specifically as solubilizing agents, nanoparticulate forms, surface modifiers, drug carriers, and also for other purposes such as diagnostic imaging agents and implants [1]. Generally, water-soluble conjugates could be well and easy designed as drug carriers for drug delivery. N-(2-hydroxypropyl)methacrylamide (HPMA) copolymer-based drug delivery systems (DDSs) are recently used for clinical applications as anticancer agents. Biologically inert poly(ethylene glycol) (PEG), approved by Food and Drug Administration (FDA) for pharmaceutical trials that is preferred in many pharmaceutical, cosmetic, and industrial applications because of its water solubility, biocompatibility, nontoxicity, and nonimmunogenicity characteristics [2]. Maleic anhydride (MA) copolymers mainly consist of MA and vinyl-based monomers. Modification/ conjugation of the anhydride copolymers is accompanied by a chemical process in which the active anhydride unit can be opened after nucleophilic attack by the ring opening reaction with amino $\left(\mathrm{R}-\mathrm{NH}_{2}\right)$ or hydroxyl functional groups (R-OH) of nucleophilic reagents [3,4-6] to obtain amide/ester and carboxylic acid structures. We often encounter the amide/carboxyl structure because of its more favorable properties in our studies. Another main goal for this conjugation reaction was getting a copolymer/drug couple with better water solubility and lower cytotoxicity properties than the free drug for improvement of its main biological activity.

For more than 50 years, several techniques have been applied in pharmaceutical industry to combine biologically active agents with polymeric materials including PEG, poly( $N$-vinyl pyrrolidone), and cellulose derivatives [7]. Ringsdorf first proposed a model (schematized in Figure 1) known by its name in 1975 for design of polymer base prodrugs [8-10]. Commercially available vinyl base poly(styrene-comaleic acid/anhydride) (SMA) is a well-known copolymer $[3,11]$. SMANCS conjugate consist of a SMA copolymer and the antitumor protein NCS (neocarcinostatin) [10,12-16].

The conjugate has also been applied in Japan for hepatocellular carcinoma treatment with significant therapeutic results and quite few side effects [17].

\footnotetext{
* To whom all correspondence should be sent: 
G. Karakus et al.: Design, synthesis, structural characterization and cell cytotoxicity of a new derivative ...

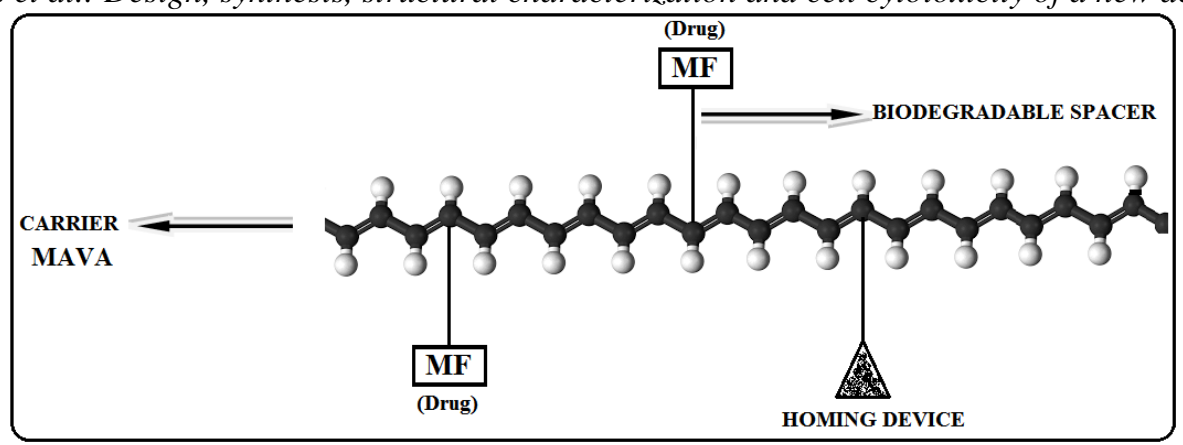

Figure 1. The Ringsdorf model.

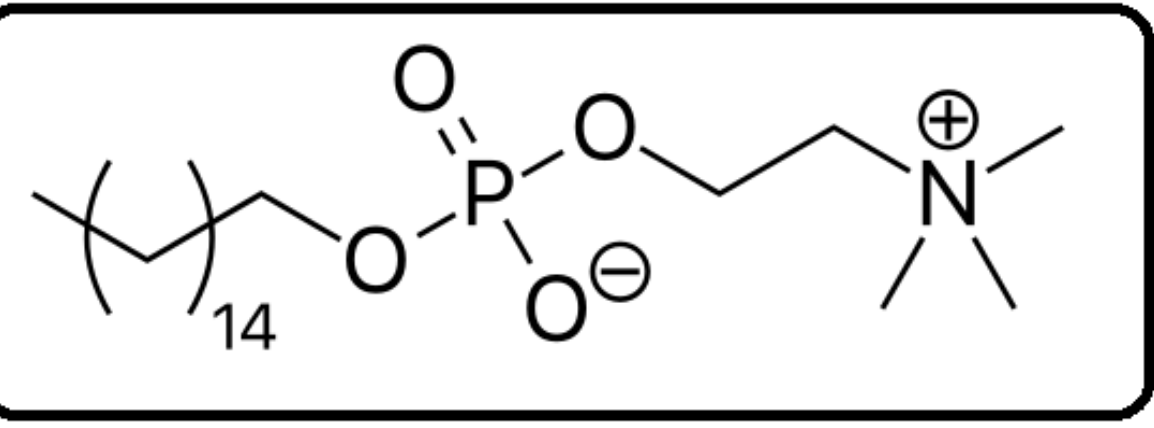

Figure 2. Chemical structure of miltefosine, MF, [2-(hexadecoxy-oxido-phosphoryl)oxyethyl-trimethyl-azanium].

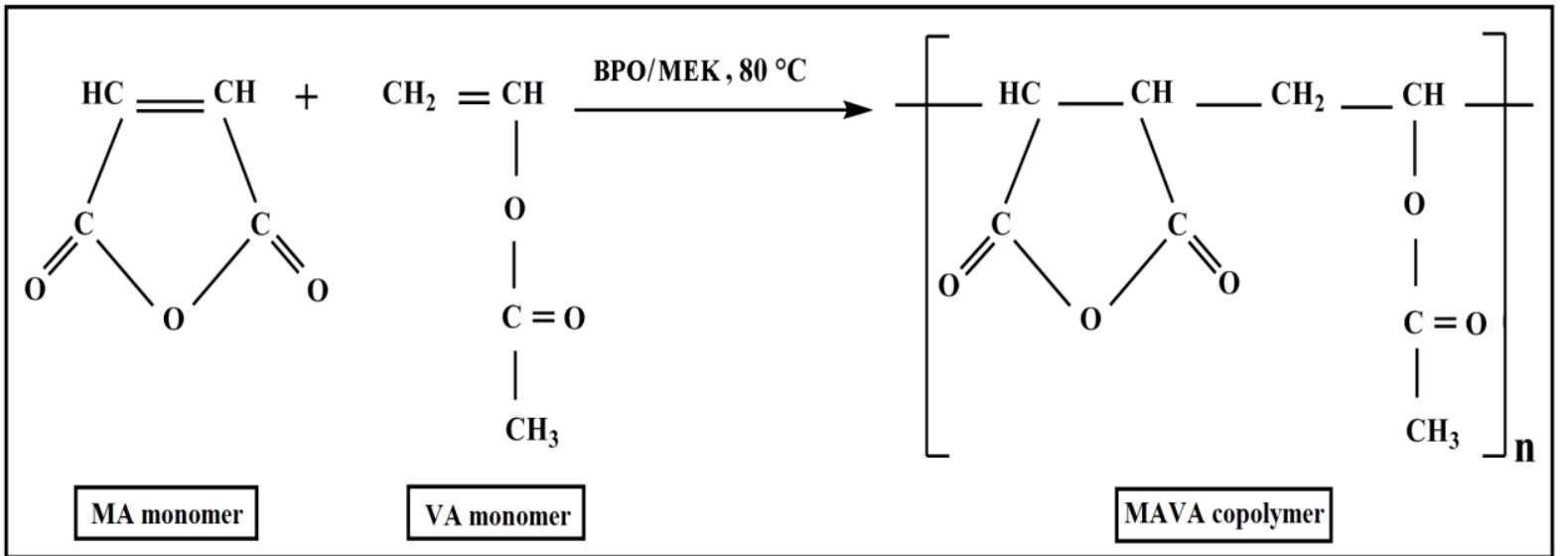

Scheme 1. Polymerization reaction mechanism of the copolymer.

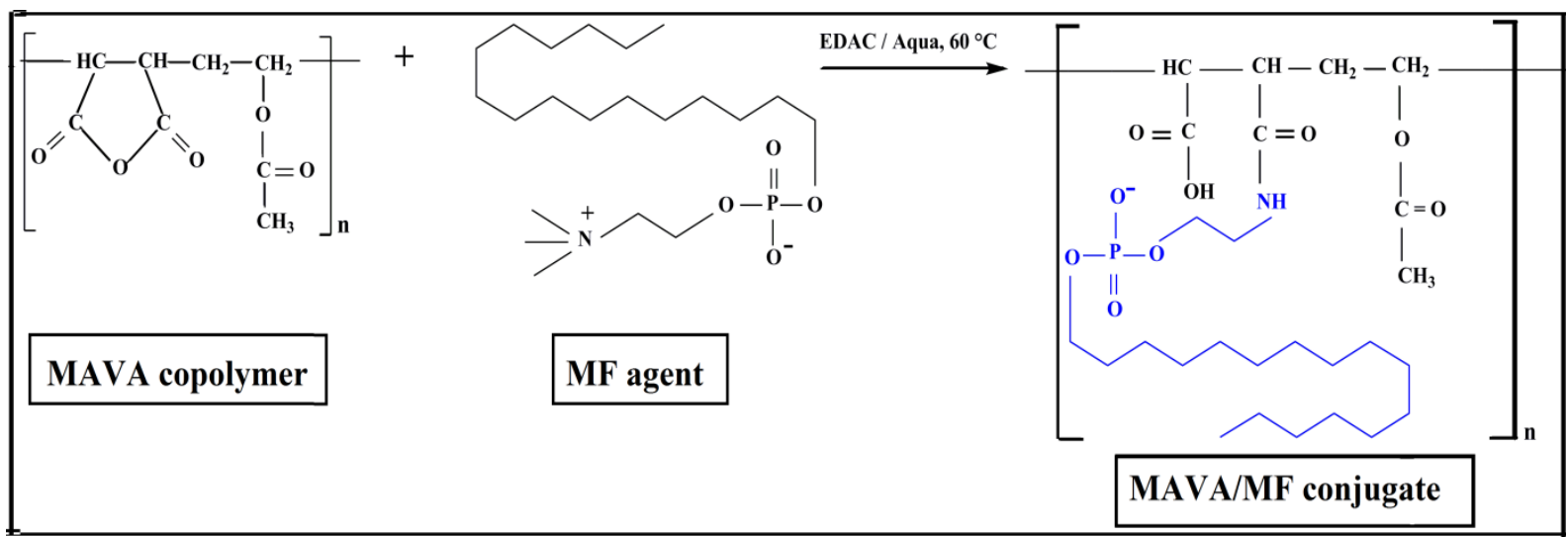

Scheme 2 Conjugation reaction of the copolymer with MF agent.

An antileishmanial drug, miltefosine [1- inhibitor of CTP: phosphocholine cytidylyl hexadecylphosphorylcholine $(\mathrm{HePC})]$ is an transferase and has antimetastatic properties. It is 
G. Karakus et al.: Design, synthesis, structural characterization and cell cytotoxicity of a new derivative... also more than $90 \%$ effective in eradicating visceral infections of Leishmania species. World Health Organization (WHO) reported that Leishmaniases, tropical diseases caused by the protozoan parasite Leishmania, are one of the six major diseases in developing countries [18]. Its systematic IUPAC name, chemical formula and molecular mass as follows: 2-(hexadecoxy-oxide-phosphoryl) oxyethyl-tri-methyl-azanium, $\mathrm{C}_{21} \mathrm{H}_{46} \mathrm{NO}_{4} \mathrm{P}, 407.568$ $\mathrm{g} / \mathrm{mol}$. Miltefosine (MF) lateral chain consists of a phosphate $\left(\mathrm{PO}_{4}{ }^{3-}\right)$ group, an intermediate ethyl chain $\left(-\mathrm{CH}_{2}-\mathrm{CH}_{2}-\right)$, known with trade names Impavido ${ }^{\circledR}$, Miltex ${ }^{\circledR}$, a trimethylamine $\mathrm{N}^{+}\left(\mathrm{CH}_{3}\right)_{3}$ group and a terminated carbon side chain (Figure 2).

In this study, as a drug carrier maleic anhydridevinyl acetate copolymer (MAVA) (Scheme 1) was chemically modified, through its reactive anhydride ring [19], by conjugation of the pharmaceutically active agent miltefosine, MF (Scheme 2). Conjugated product was named MAVA/MF. Cell cytotoxic effect of MAVA/MF was also studied with MAVA and MF cytotoxicity by using a healthy L929 mouse fibroblast cell line. Cytotoxicity experiments showed that MAVA/MF conjugate had no cytotoxicity when cell viability was taken into consideration even at $250 \mu \mathrm{g} / \mathrm{mL}$ concentration.

\section{EXPERIMENTAL}

\section{Materials}

Synthesis, Conjugation and Purification: Chemicals were obtained from Merck (Schuchardt,

Table 1 Synthetic reaction conditions of copolymer and conjugated product.

\begin{tabular}{|c|c|c|c|c|c|}
\hline 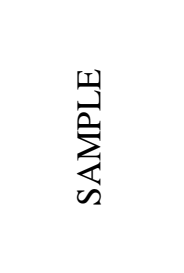 & 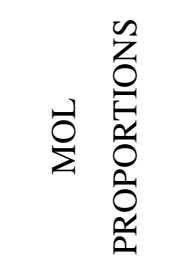 & 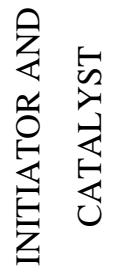 & 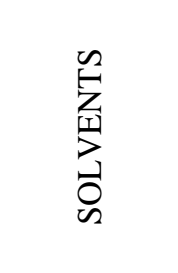 & $\sum_{ٍ}^{\Perp}$ & 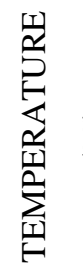 \\
\hline \multirow{2}{*}{ MAVA } & MA:VA & \multirow{2}{*}{$\mathrm{BPO}$} & \multirow{2}{*}{ MEK } & \multirow{2}{*}{24} & \multirow{2}{*}{80} \\
\hline & $\sim(1: 1)$ & & & & \\
\hline \multirow{2}{*}{ MAVA/MF } & MAVA:MF & \multirow{2}{*}{ EDAC } & \multirow{2}{*}{$\begin{array}{c}\text { Water } \\
\text { (ultra pure) }\end{array}$} & \multirow{2}{*}{48} & \multirow{2}{*}{60} \\
\hline & $\sim(1: 1)$ & & & & \\
\hline
\end{tabular}

\section{Synthesis and Purification of MAVA/MF Conjugate}

MAVA/MF conjugate was designed by the modification of MAVA copolymer with miltefosine (MF, mol. mass: $407.568 \mathrm{~g} / \mathrm{mol}$ ), at a 1:1 [6,22] molar ratio for $48 \mathrm{~h}$ at $60{ }^{\circ} \mathrm{C}$ in ultra-pure water, using EDAC [N-(3-dimethyl-aminopropyl)- $N$ '-
Germany) are as follows: MA (maleic anhydride), MEK (methyl ethyl ketone), EDAC [N-(3dimethyl-aminopropyl)-N'-ethylcarbodiimide hydrochloride] and BPO (benzoyl peroxide). Ethyl alcohol (95\%) was purchased from Carlo-Erba (Rodano, Italy). $\mathrm{NaOH}$ (sodium hydroxide), $\mathrm{HCl}$ (hydrochloric acid), VA (vinyl acetate), ethyl acetate and petroleum ether were ordered from Sigma-Aldrich (St. Louis, USA). Miltefosine was supplied by Orphanidis Pharma Research $\mathrm{GmbH}$ (Vienna, Austria).

Cultivation of L929 Mouse Fibroblast Cells and Cell Proliferation Assay: DMEM (Dulbecco's minimum Eagle medium) and fetal calf serum (10\%) were obtained from Sigma (St. Louis, MO, USA), and WST-1 labeling reagent was purchased from Roche (Mannheim, Germany).

\section{Synthesis and Purification of MAVA Copolymer}

As described in our previous study [20], MAVA was synthesized traditionally by free radical chain polymerization reaction in the presence of MA and VA monomers. Table 1 summarizes the reaction conditions (briefly: 1:1 monomer molar ratio, MEK organic solvent, BPO free radical initiator, $24 \mathrm{~h}$, and $80^{\circ} \mathrm{C}$ ). Unreacted or homopolymer products were gently removed by incubating the white precipitated conjugate in ethyl acetate $(24 \mathrm{~h})$. Petroleum ether precipitation, under vacuum filtration, and vacuum incubator drying at $55{ }^{\circ} \mathrm{C}, 24 \mathrm{~h}$ were carried out for purification [21]. 
G. Karakus et al.: Design, synthesis, structural characterization and cell cytotoxicity of a new derivative ...

room for interacting all of the anhydride repeated units with concentrated $\mathrm{NaOH}$ [11]. Copolymer was expected to dissolve/hydrolyze in alkaline water medium and turn to a homogeneous transparent mixture which was immediately cooled again to room temperature, then the $\mathrm{pH}$ was reduced to 5 by drop-wise adding of $1 \mathrm{M} \mathrm{HCl}$. Modified sample was prepared using the mixed solvent (5\% ethyl alcohol/injectable water, stored at $-20{ }^{\circ} \mathrm{C}$ until the adding step) [18] by drop-wise addition of $\sim 10 \mathrm{mg} / \mathrm{mL}$ solution of MF. Initiation reaction was started by adding EDAC $(20 \mathrm{mg} / \mathrm{mL}$ solution) over $15 \mathrm{~min}, \mathrm{pH}$ was kept at 5 by adding $0.01 \mathrm{M} \mathrm{HCl}$ [11]. The reaction medium was then allowed to proceed for $24 \mathrm{~h}$ at $50{ }^{\circ} \mathrm{C}$ in a continuously shaking condition to get a viscous blurry white solution in a dark room, and allowed further for $48 \mathrm{~h}$ at $60^{\circ} \mathrm{C}$. The products were washed several times with excess of cold ethanol and incubated/cooled for $1 \mathrm{~h}$ at $-20^{\circ} \mathrm{C}$. White precipitate was then collected (centrifugation, $10 \mathrm{~min}, 3,000$ $\mathrm{rpm}$ ) in powder form after the liquid phase was removed and purified in a vacuum incubator $(24 \mathrm{~h}$, $\left.55^{\circ} \mathrm{C}\right)[23]$.

\section{Structural Characterization}

The infrared spectrum of the samples (copolymer and MAVA/MF conjugate) were recorded as $\mathrm{KBr}$ pellets on a FTIR spectrophotometer (Unicam MATTSON 1000, USA) at $400-4000 \mathrm{~cm}^{-1}$ with increments adjusted to $4 \mathrm{~cm}^{-1}$. The nuclear magnetic resonance analyses, ( ${ }^{1} \mathrm{H}-\mathrm{NMR}$ and $\left.{ }^{31} \mathrm{P}-\mathrm{NMR}\right)$ were performed on a Bruker Avance III instrument (Karlsruhe, Germany) at $400 \mathrm{MHz}$ using $6 \mathrm{mg}$ of the samples, dissolved in $0.8 \mathrm{~mL}$ of heavy water $\left(\mathrm{D}_{2} \mathrm{O}\right)$.

\section{Size-Exclusion Chromatography (SEC) of Copolymer/Drug Conjugate}

As detailed in our previous study [23], average molecular weight distribution of the copolymer and modified product was measured by a Viscotek size exclusion chromatography (SEC) system (Houston, USA) with $660 \mathrm{~nm}$ refractive index and $670 \mathrm{~nm}$ right-angle light scattering (RALS) apparatus. Polystyrene standard was used for quadruple detector array calibration. Powdered samples were prepared in tetrahydrofuran (THF) and eluted (1.0 $\mathrm{mL} / \mathrm{min}$ ) at room temperature. OmniSEC 4.1 software program (Viscotek Cooperation, Houston USA) was used for obtained data analysis [24,25].

\section{Cytotoxicity of MAVA Copolymer and MAVA/MF Conjugate}

Cultivation of L929 mouse fibroblast cell lines: Detailed information about this method can be obtained from our previous work [35]: L929 (ATCC cell line, NCTC clone 929) mouse connective tissue fibroblast cell line, was cultured in DMEM, in the presence of fetal calf serum $(10 \%)$ and L-glutamine $(2 \mathrm{mM} / \mathrm{ml})$ without adding antibiotics to the cell culture medium. Cultivation was performed for the cultures in the humidified incubator at $37{ }^{\circ} \mathrm{C}$ and $5 \% \mathrm{CO}_{2}$, until complete cell monolayer integration ( 7 days).

Cell proliferation assay: As we clearly explained in our previous study [35], the cell proliferation assay mainly measures the number of living cells by dividing the tetrazolium salts to formazan by cellular enzymes in presence of the WST-1 labeling reagent. This method is based on a simple and well known kit protocol [35]. Briefly, after the user's kit protocol, quantification was performed by a scanning multi-well spectrophotometer (wavelength $450 \mathrm{~nm}$ ) according to the absorbance measurement of the dye solution. Seeded cells in 96-well microtiter plates were adjusted to $1 \times 10^{5}$ cells $/ \mathrm{mL}$ in a main volume of 100 $\mu \mathrm{L}$ per well. For the cytotoxic analysis of the MAVA; MF, and MAVA/MF 500, 250, 125, 62.5, 31.2 , and $15.6 \mu \mathrm{g} / \mathrm{mL}$ concentrations were applied. Incubation was performed for $24 \mathrm{~h}$ at $37^{\circ} \mathrm{C}$ in a humidified atmosphere with $5 \% \quad \mathrm{CO}_{2}$. After the incubation period, WST-1 labeling reagent was gently supplemented to the medium as $1: 1$ volume ratio $(10 \mu \mathrm{l})$ in each well. The absorbance values, using the control group comparison, were recorded at $450 \mathrm{~nm}$ using a Thermo Scientific microplate photometer (Multiskan FC, USA). Ten $\mu$ l of WST1 labeling reagent/one hundred $\mu \mathrm{l}$ of medium was also added to one well (selected blank position) on ELISA reader for background control purpose. After the start of the tetrazolium reaction $(2 \mathrm{~h})$ absorbance was recorded and experiments were carried out in six replicates for reliable results. Percentage viability was calculated according to user's manual and following Eq. (1) the optical density (OD) of the test products was compared with that of the negative control.

Cell Viability $(\%)=[(\mathrm{OD} 450 \quad($ Sample $) / O D 450$ $($ Negative control) $) \times 100]$

\section{Statistical analysis}

Optical density (OD) results, with six replicates, were presented as mean \pm SD. Statistical ANOVA (one-way analysis of variance) was performed with 95\% confidence levels for multiple comparisons. Furthermore, Student's $t$-test was also used for two group comparisons. 
G. Karakus et al.: Design, synthesis, structural characterization and cell cytotoxicity of a new derivative...

RESULTS AND DISCUSSION

\section{FTIR Analysis}

Unmodified copolymer (Figure 3a) had the main anhydride containing polymer structure [26-31]: symmetric and asymmetric carbonyl $(\mathrm{C}=\mathrm{O})$ stretches of MA at $1855.48 \mathrm{~cm}^{-1}$, and $1780.59 \mathrm{~cm}^{-1}$, respectively $[26,27]$. Frequency vibrations of $\mathrm{C}-\mathrm{O}-$ $\mathrm{C}$ bond on anhydride ring were found at 1025.21 $\mathrm{cm}^{-1}$ and $934.96 \mathrm{~cm}^{-1}$ [28]. Another carbonyl $(\mathrm{C}=\mathrm{O})$ symmetric and asymmetric stretches of VA was at $1715.67 \mathrm{~cm}^{-1}$ [29], $\mathrm{CH}_{3}$ and $\mathrm{CH}_{2}$ belong to VA stretching frequencies at $1373.80 \mathrm{~cm}^{-1}$ and 1430.38 $\mathrm{cm}^{-1}$, respectively $[30,31]$, characteristic acetyl ($\mathrm{COCH}_{3}$ ) group stretching frequencies of VA were at $1095.30 \mathrm{~cm}^{-1}$ [26], C-C vibration at $603.84 \mathrm{~cm}^{-1}$, $\mathrm{C}-\mathrm{O}-\mathrm{C}$ stretching at $1214.91 \mathrm{~cm}^{-1}$, and $\mathrm{C}-\mathrm{H}$ group stretching vibration at $2943.19 \mathrm{~cm}^{-1}[32,33]$.

Characteristic copolymer repeating units disappeared almost completely in MAVA/MF as a sign of the success of the ring-opening reaction (Figure $3 \mathrm{~b}$ ). It also means that a high percentage of the repeated anhydride rings were modified after copolymer hydrolysis and nucleophilic amino ($\mathrm{NH}_{2}$ ) group attack of MF [34]. Modification/conjugation of anhydride ring generally accompanied by functional group formation, for example, results in carboxylic group with amide or ester structure [34]. In this study conjugation reaction was verified with formation of a carboxylic acid and amide functionality. Characteristic - $\mathrm{CH}$ stretching vibration of VA along with the copolymer backbone stretching vibrations at $1403 \mathrm{~cm}^{-1}$ [35], CO-O-C ester groups or C-C of VA located at $1226.97 \mathrm{~cm}^{-1}$, and a $\mathrm{CH}_{2}$ deformation at $1585 \mathrm{~cm}^{-1}$ [36]. Peak observed at $1755 \mathrm{~cm}^{-1}$ could be assigned to $-\mathrm{COOH}$ carboxylic acid units [32]. $1394.31 \mathrm{~cm}^{-1}$ could be associated with MF because the same peak was also observed on pure MF spectrum. Peak $1066.28 \mathrm{~cm}^{-1}$ belongs to $\mathrm{PO}_{4}{ }^{3-}$ antisymmetric stretching frequency [37-43], $117267 \mathrm{~cm}^{-1}$ and $1052.22 \mathrm{~cm}^{-1}$ were also assigned to $\mathrm{PO}_{4}{ }^{3-}$ antisymmetric stretching movement [44]. According to literature, Breitinger and co-workers emphasized that the deceptively simple strong vibrations centered at $1059 \mathrm{~cm}^{-1}$ including minimum four components of inorganic phosphate
$\left(\mathrm{PO}_{4}\right)$, were produced by removal of the threefold degeneracy of $\mathrm{PO}_{4}$ and activation of the general mode of phosphate $\left(\mathrm{PO}_{4}\right)$ [44]. Furthermore, 629.77 $\mathrm{cm}^{-1}$ was detected in the spectrum, because a series of infrared bands such as $620 \mathrm{~cm}^{-1}, 643 \mathrm{~cm}^{-1}$ and $673 \mathrm{~cm}^{-1}$ were assigned to out of vibrations of plane bending vibrational mode of the phosphate anion $\left(\mathrm{PO}_{4}{ }^{3-}\right)$ and peak $892 \mathrm{~cm}^{-1}$ was associated with water vibrational modes [44]. Because the vibrational frequencies around $1577 \mathrm{~cm}^{-1}$ could be an overtone/combination band, the observed peak $1585.82 \mathrm{~cm}^{-1}$ was also considered as overtone and combination [44].

In addition to multiple phosphate vibrational modes detection, observed peaks were assigned to $\mathrm{PO}_{4}{ }^{3-}, \mathrm{OH}$, and $\mathrm{H}_{2} \mathrm{O}$ stretching and bending modes. Conjugate, MAVA/MF, consists of main polymeric backbone linked by $\mathrm{PO}_{4}$ groups of miltefosine through an amide bond. As a result, at the molecular level there are phosphate units which are not equivalent in the conjugate structure. Peak located at $3662.75 \mathrm{~cm}^{-1}$ could be attributed to both primary amide and also carboxylic acid groups related to the most evident vibrational peak for conjugation reaction.

As reported previously by Das and co-workers, Figure $3 \mathrm{c}$ presents the IR spectra of the pure miltefosine. Peak assignments for the characteristics of MF: at $1471 \mathrm{~cm}^{-1}$ (bending vibrations for $-\mathrm{CH}_{2}$ ) and $1242 \mathrm{~cm}^{-1}$ (asymmetric stretching vibrations for $-\mathrm{PO}_{2}$ ) and overlap of 1078 $\mathrm{cm}^{-1}$ (symmetric stretching vibrations for $-\mathrm{PO}_{2}^{-}$) and $1064 \mathrm{~cm}^{-1}$ (stretching vibrations for $\mathrm{P}-\mathrm{O}-\mathrm{C}$ ) were detected in the solid state, crystalline form, of the drug MF [45].

\section{NMR Analysis}

${ }^{1} H$-NMR Analysis: ${ }^{1} \mathrm{H}-\mathrm{NMR}$ spectrum of the copolymer (Figure 4a) showed the characteristic peaks as follows: chemical shift belongs to protons of anhydride rings at $3-4 \mathrm{ppm},-\mathrm{CH}_{2}$ protons on VA approximately at $\sim 2.3-2.7 \mathrm{ppm},-\mathrm{CH}$ fragment (bound directly to oxygen) produced a multiplet peak at around $\sim 4.9-5.3 \mathrm{ppm}[46,47]$, and all of the $-\mathrm{CH}_{3}$ protons, adjacent to $\mathrm{C}=\mathrm{O}$ (carbonyl group), located at $\sim 1.7-2.0 \mathrm{ppm}[48-50]$. 


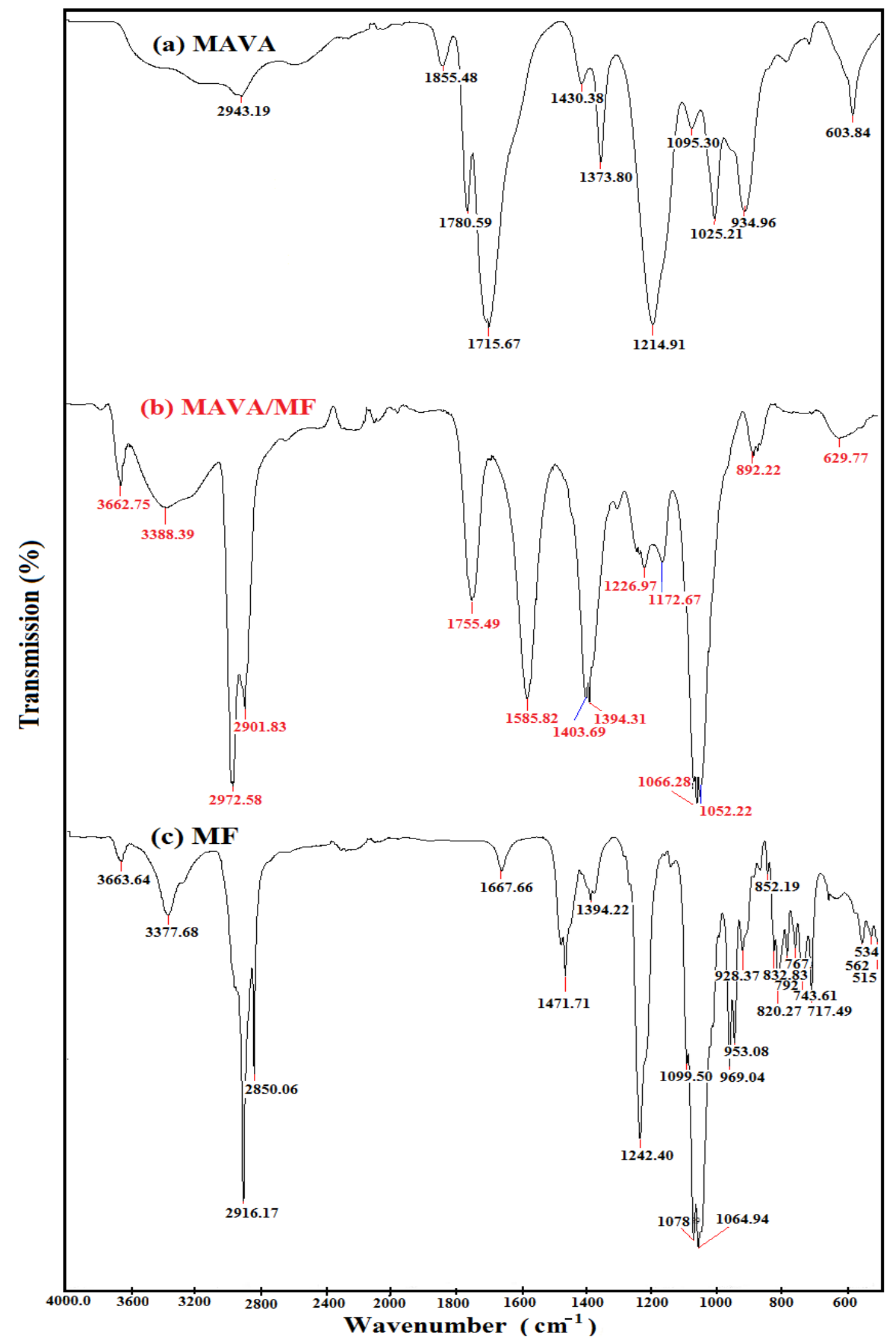

Figure 3. FTIR spectra of the copolymer, conjugation product, and MF agent. (a) MAVA, (b) MAVA/MF, and (c) MF 
G. Karakus et al.: Design, synthesis, structural characterization and cell cytotoxicity of a new derivative ...<smiles>CC1C(=O)OC(=O)C1CC1CCC(C)(C)O1</smiles>

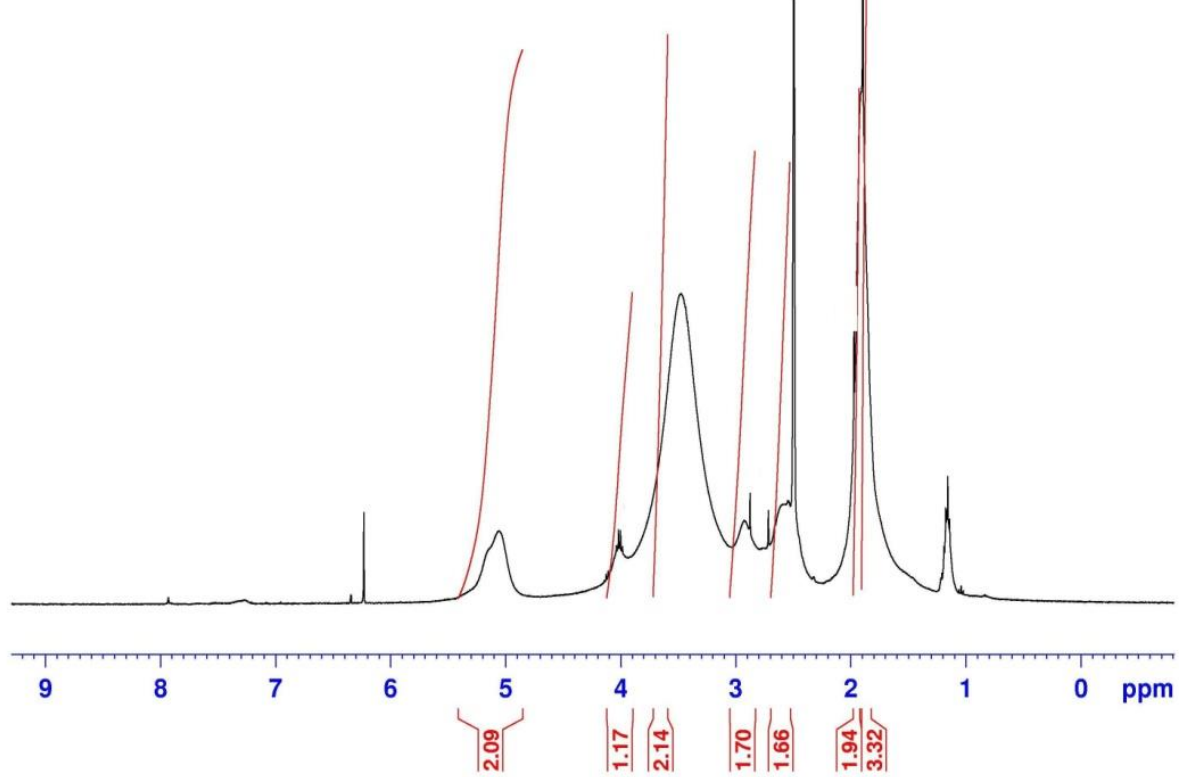

(a)

MAVA / MF

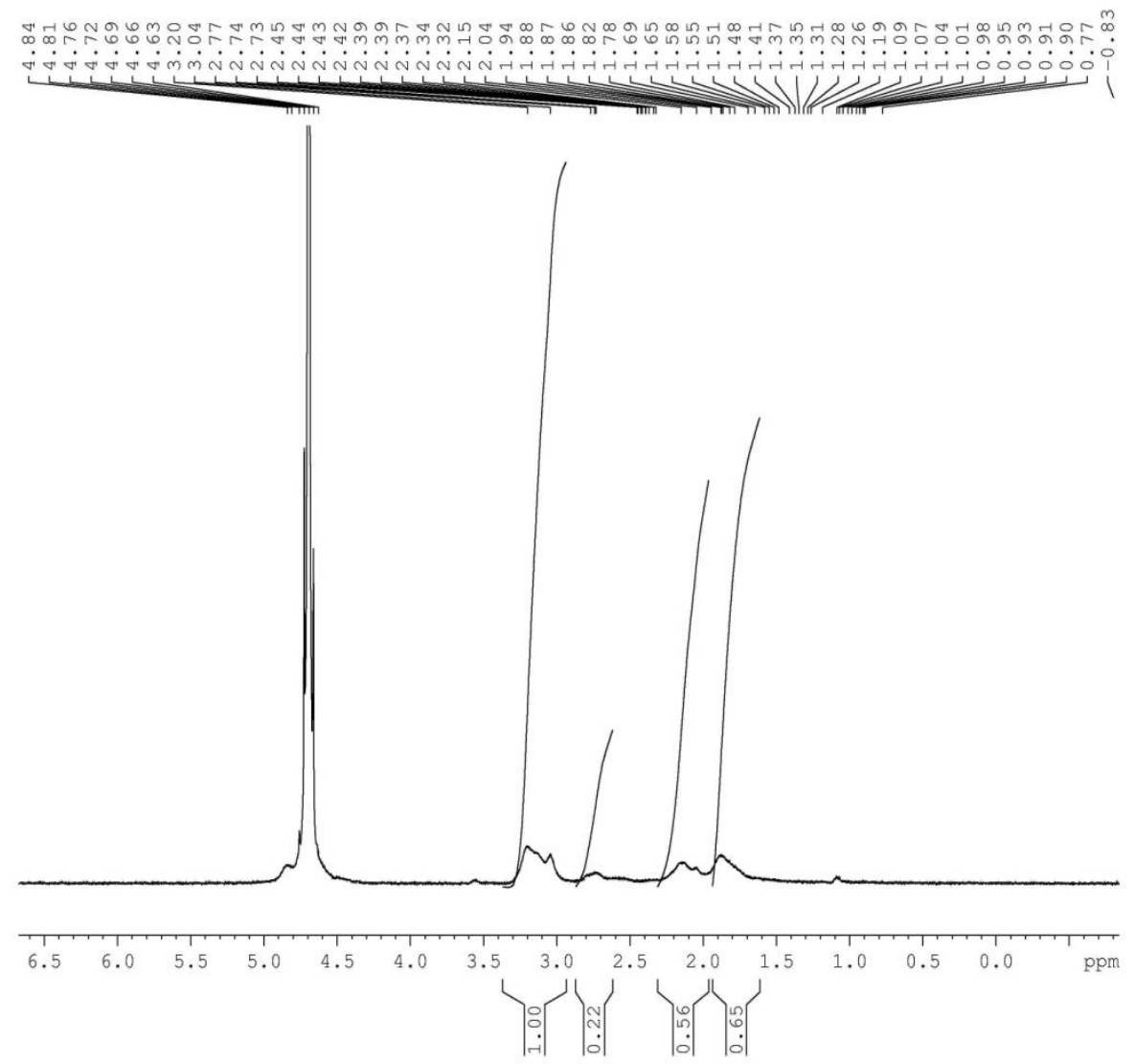

(b) 
G. Karakus et al.: Design, synthesis, structural characterization and cell cytotoxicity of a new derivative ... MF

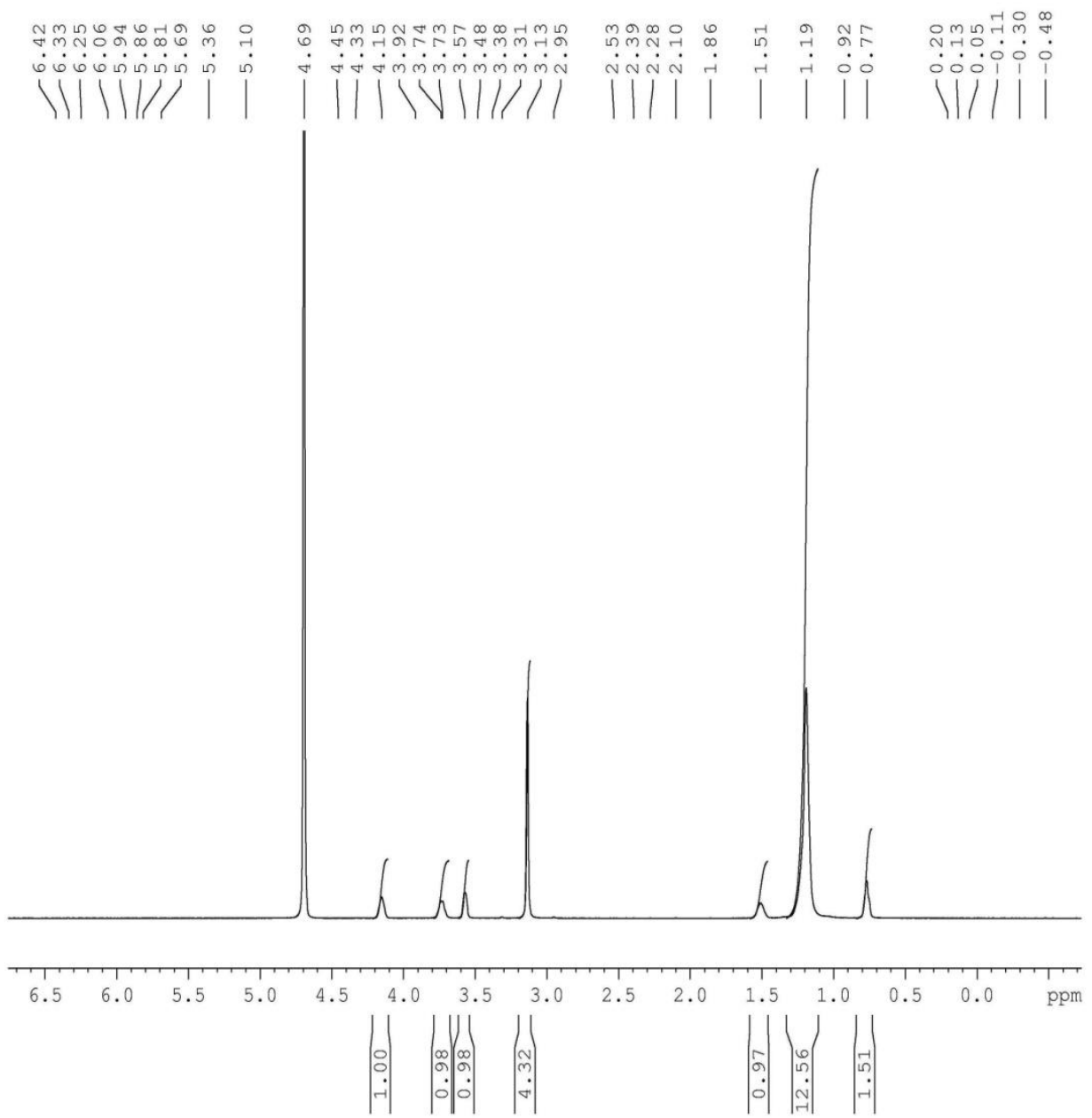

Figure 4. ${ }^{1} \mathrm{H}-\mathrm{NMR}$ spectra of the copolymer, conjugation product, and MF agent.

(c) (a) MAVA, (b) MAVA/MF, and (c) MF.

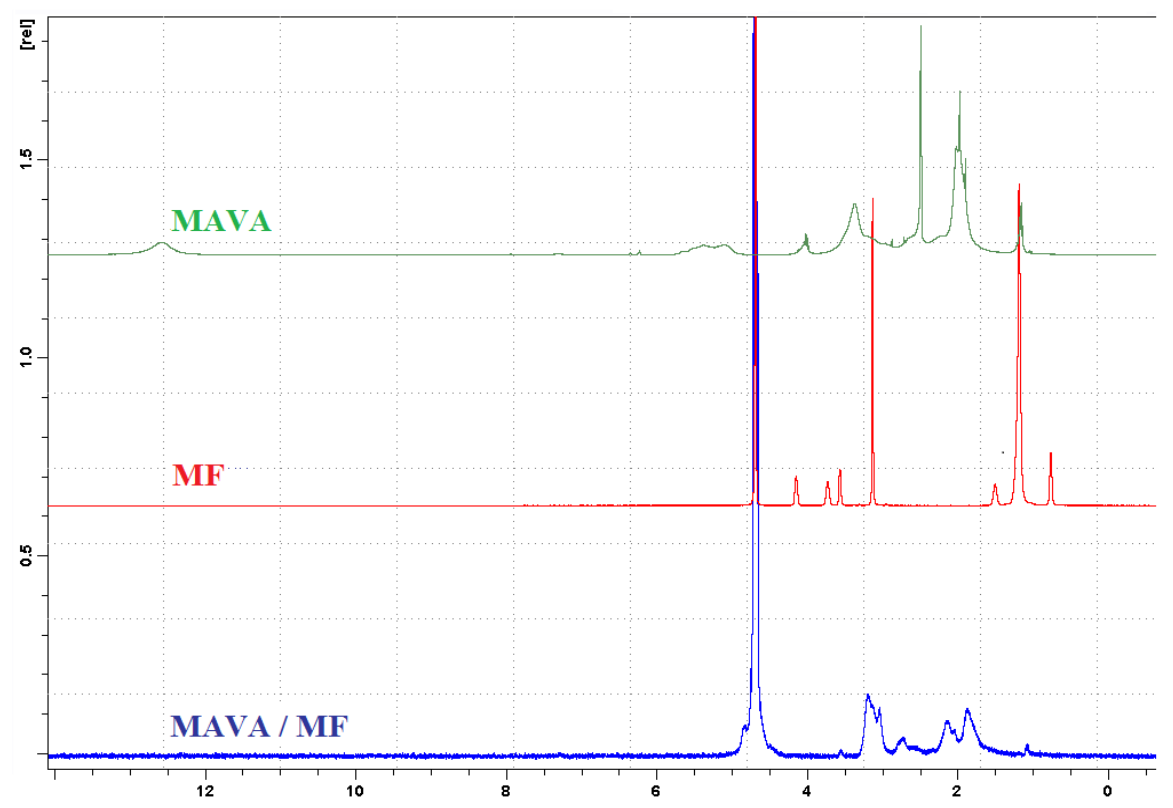

Figure 5. Overlapped ${ }^{1} \mathrm{H}-\mathrm{NMR}$ spectra of the three components MAVA, MF and MAVA/MF. 
G. Karakus et al.: Design, synthesis, structural characterization and cell cytotoxicity of a new derivative ...

MAVA / MF

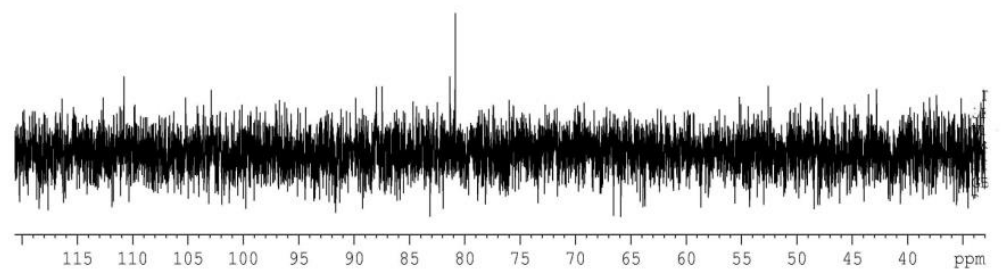

(a)

MF

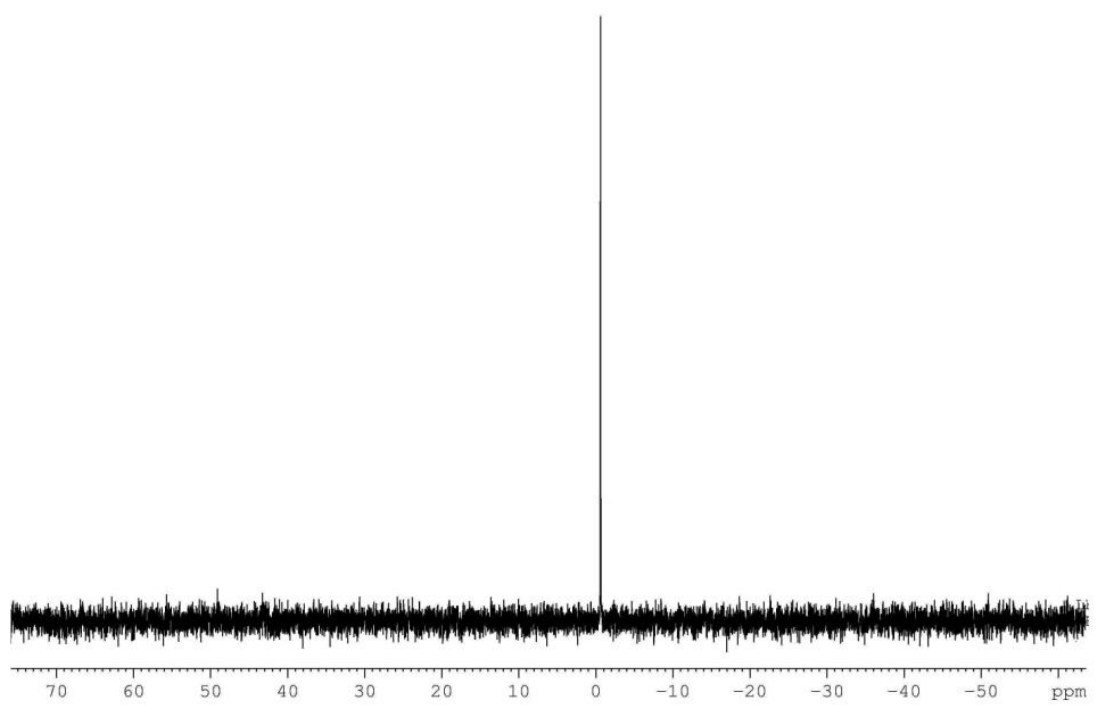

(b)

Figure 6. ${ }^{31} \mathrm{P}-\mathrm{NMR}$ spectra of the conjugation product and MF agent.(a) MAVA/MF and (b) MF.

MAVA/MF conjugate (Figure $4 \mathrm{~b}$ ) peaks are as follows: aliphatic $-\mathrm{CH}_{3}$ peaks of both copolymer backbone and end group of MF appeared at 2.77 ppm. It is taken into account that possible intramolecular hydrogen bonds with direct $-\mathrm{NH}$ and $-\mathrm{OH}$ fragments could not produce completely integrated peaks. Because the $-\mathrm{NH}$ peaks of amide linkage, evidence for the success of the chemical conjugation reaction, were masked/overlapped by the organic solvent peak at around 5.0-8.5 ppm, therefore, they were not detected. However, peaks observed at $4.84 \mathrm{ppm}$ were assigned to amide linkage considering amide were overlapped by the solvent in the 4.63-4.84 $\mathrm{ppm}$ range with a slight 
G. Karakus et al.: Design, synthesis, structural characterization and cell cytotoxicity of a new derivative...

difference in chemical shift. $\mathrm{D}_{2} \mathrm{O}$ solvent peaks were observed at $4.76 \mathrm{ppm}$ [51] and $4.81 \mathrm{ppm}$ (TSP). $-\mathrm{CH}_{2}$ protons intensity on VA and MF appeared at 1.31-1.37 ppm. Peak range 2-3 ppm was attributed to the $\mathrm{RNH}-\mathrm{CH}_{2}-(\mathrm{C}$ is attached directly to $\mathrm{N}$ ) as a marker of conjugation reaction, because the copolymer does not include any $\mathrm{N}$ atom. Due to the most important evidence of chemical modification of the copolymer with MF, $1.19,1.26$ and $1.28 \mathrm{ppm}$ could be assigned to characteristic $\mathrm{P}-\mathrm{O}-\mathrm{CH}_{2}$ - linkage resulting from $\mathrm{MF}$ (Figure 4c) on the conjugate [52]. As can be clearly seen from the overlapped spectrum (Figure 5), both copolymer and MF chemical shifts were overlapped at around $1-5 \mathrm{ppm}$ range. The most evident peak in the ${ }^{1} \mathrm{H}-\mathrm{NMR}$ for the conjugation and also ring opening reaction of anhydride ring, shows the presence of phosphorus chemical shifts in the newly synthesized conjugate. All results proved that amide linkages and phosphorus on MAVA/MF were confirmed by ${ }^{1} \mathrm{H}-\mathrm{NMR}$ and FTIR spectra. However, this conjugation reaction should be supported by a more detailed analysis like ${ }^{31} \mathrm{P}-$ NMR analysis.

${ }^{31}$ P-NMR Analysis: Phosphorus-31 nuclear magnetic resonance ( $\left.{ }^{31} \mathrm{P}-\mathrm{NMR}\right)$ is theoretically the same as ${ }^{1} \mathrm{H}-\mathrm{NMR}$ spectroscopy. The ${ }^{31} \mathrm{P}$ nucleus is useful in NMR spectroscopy due to its relatively high gyromagnetic ratio. Moreover, ${ }^{31} \mathrm{P}$ has a $100 \%$ natural isotopic abundance property. Similar to the ${ }^{1} \mathrm{H}$ nucleus, the ${ }^{31} \mathrm{P}$ nucleus has a nuclear spin of $\pm 1 / 2$ which makes spectra relatively easy and fast to interpret. As the phosphorus nucleus is coupled to a hydrogen nucleus bound directly to it, that is, this coupling separated by a single bond, is expected to be very high. Figure 6a shows the MAVA/MF spectrum, only one peak observed again at $80.83 \mathrm{ppm}$ for $\mathrm{PO}_{4}^{-3}$ with some phosphorus chemical shift. It can be said that conjugation reaction is verified by ${ }^{31} \mathrm{P}-\mathrm{NMR}$ due to phosphorus presence on the conjugate. Figure $6 \mathrm{~b}$ shows a poor MF spectrum, only one peak observed at $0.66 \mathrm{ppm}$ for $\mathrm{PO}_{4}^{-3}$ that is an evidence of phosphorus presence [53]. Overlapped ${ }^{31} \mathrm{P}-\mathrm{NMR}$ spectrum is also provided for the free and conjugated MF to compare both spectra (Figure 7).

It should be stressed that ${ }^{31} \mathrm{P}-\mathrm{NMR}$ is an excellent technique for studying phosphorus containing compounds, such as small organic compounds, metal coordination complexes, high molecular weight molecules, etc. Size-exclusion chromatography (SEC) was used for approximate molecular weights $(\mathrm{Mw})$ measurement of pure copolymer and conjugated copolymer. Results obtained for MAVA copolymer: $3.98 \times 10^{5} \mathrm{Da}$ and MAVA/MF conjugate: $1.39 \times 10^{6} \mathrm{Da}$ (Da: daltons) are promising. SEC results confirmed that the molecular weight of conjugated copolymer with $\mathrm{MF}$, reached almost threefold percentage, by the conjugation of MF to the copolymer backbone.

\section{Supposed Reaction Mechanism for the Copolymer and Conjugate}

Basic FTIR, ${ }^{1} \mathrm{H}-\mathrm{NMR}$ and ${ }^{31} \mathrm{P}-\mathrm{NMR}$ spectroscopic analysis and obtained highly watersoluble characteristic of the conjugated product revealed that copolymer synthesized by free-radical polymerization and conjugation mechanism was in agreement with the assumption that the MF molecule was bound to the copolymer backbone by a ring-opening reaction (Schemes 1 and 2, respectively).

\section{Average Molecular Weight Distribution of Copolymer/Drug Conjugate}

Molecular weights of the MAVA copolymer and MAVA/MF conjugate were $\sim 184$ and $\sim 548 \mathrm{gmol}^{-1}$, respectively.

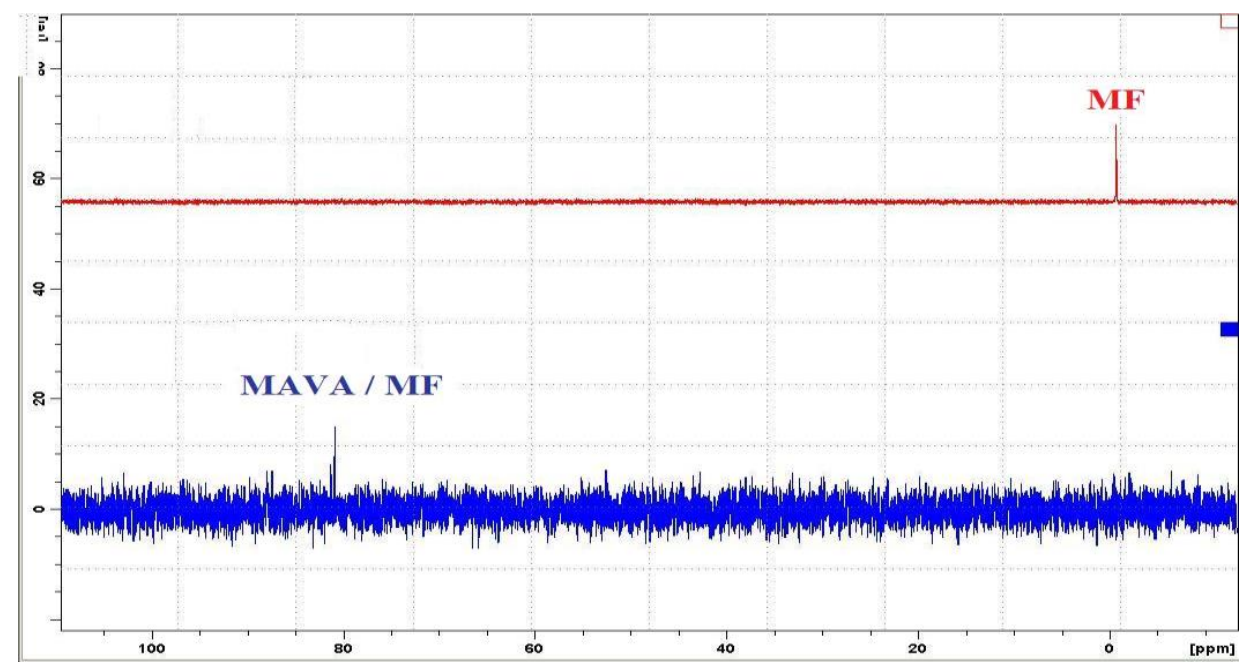

Figure 7. Overlapped ${ }^{31} \mathrm{P}-\mathrm{NMR}$ spectra of the two components MF and MAVAMF. 
G. Karakus et al.: Design, synthesis, structural characterization and cell cytotoxicity of a new derivative...

Cytotoxicity of MAVA Copolymer and MAVA/MF Conjugate

Cytotoxicity of agents: Quantitative analysis, according to WST-1 cytotoxicity test $(24 \mathrm{~h})$, were implemented for copolymer (MAVA), MF, and conjugate (MAVA/MF) (Figure 8).

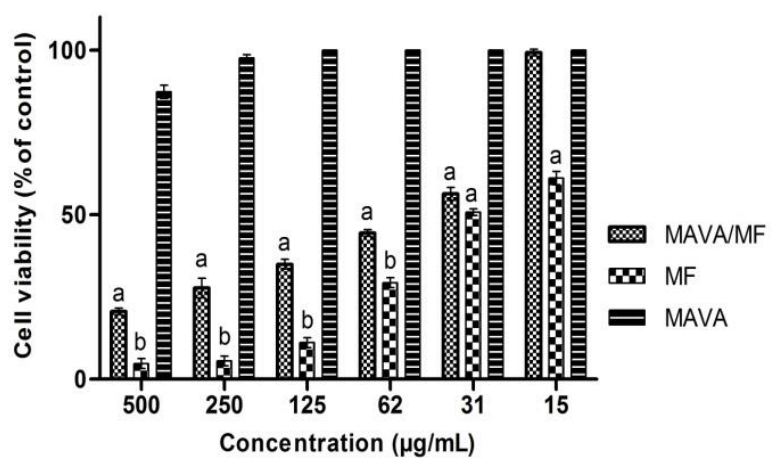

Figure 8. In vitro cytotoxic effect of the copolymer, MF, and MAVA/MF conjugate on L929 fibroblast cells lines. a $\mathrm{P}<0.05$ vs control. ${ }^{\mathrm{b}} \mathrm{P}<0.05$ vs control, MAVA/MF 500, 250, 125 and $62.5 \mathrm{mg} / \mathrm{mL}$.

The figure clearly shows that even at the highest concentration $(500 \mu \mathrm{g} / \mathrm{mL})$ of the copolymer, there was no adverse effect on living cells. The cytotoxicity results of MF and MAVAlMF 500, $250,125,62.5 \mathrm{mg} / \mathrm{mL}$ were compared with the control group for statistical evaluation, and were found significantly different $(\mathrm{P}<0.05)$ (Figure 8$)$. It could be said for the cytotoxicity as follows: MF $>$ MAVA $>$ MAVA/MF (at 500, 250, 125, 62 and $31 \mathrm{mg} / \mathrm{mL}$ ) and MF>MAVA=MAVA/MF (at 15 $\mathrm{mg} / \mathrm{mL}$ ). MAVA/MF copolymer/drug couple was successfully designed with less cytotoxicity than the free drug (MF).

\section{CONCLUSIONS}

To design a new copolymer/drug conjugate, nontoxic vinyl base copolymer (MAVA) was selected as the biocompatible drug carrier for MF. Chemical conjugation of the selected biologically active compound, MF (antileishmanial drug), was achieved by ring-opening reactions.

Potential toxicity measurement is generally used for the investigation of the viability effects of test compounds on the cells grown for a drug candidate. Synthetic polymers are considered to be promising materials for biomedical applications. Cell cytotoxicity assays of MAVA, MF, and MAVA/MF were carried out by quantitative WST1 test $(24 \mathrm{~h})$. As a promising result it was observed that MAVA did not damage cell viability even at its highest concentration $(500 \mu \mathrm{g} / \mathrm{mL})$. The cytotoxicity results of MF and MAVA/MF 500, $250,125,62.5 \mathrm{mg} / \mathrm{mL}$, by comparing with control group, were found to be statistically significantly different $(\mathrm{P}<0.05)$.

Promising results should be emphasized, considering that MF is a highly toxic drug, that MAVA/MF had no cytotoxicity and is synthesized economically in a short time.

The initial goal of this experiment was to obtain a less/non-toxic drug having high water-soluble characteristics by comparing with free MF. On the other hand, preserving the original characteristics of miltefosine in the conjugate is a crucial step for rational copolymer/drug design.

In this study, in the direction of our main goal the conjugation reaction for copolymer/drug couple was successfully carried out with better water solubility and also less cytotoxicity than the free drug. We also hope that the biological activity of this conjugate (MAVA/MF) will be higher than that of the free drug (MF) with more comprehensive biological tests to be performed.

Acknowledgement: In this study, the polymeric samples, MAVA and MAVA/MF, were synthesized in the Research Center (CUTFAM), Cumhuriyet University, Faculty of Medicine (Sivas, Turkey). FTIR and NMR analysis were carried out at the Technology Research and Developing Centre (TAUM), Erciyes University (Kayseri, Turkey). Molecular weight measurements of the samples were performed by SEC (Size-Exclusion Chromatography) analysis at Yildiz Technical University (Istanbul, Turkey).

Disclosure Statement: The authors of the manuscript solemnly declare that no scientific and/or financial conflicts of interest exist with other people or institutions.

\section{REFERENCES}

1. I. Popescu, D.M. Suflet, I.M. Pelin, G.C. Chitanu, Rev. Roum. Chim., 56, 173 (2011).

2. T. Minko, Drug. Discov. Today Tech., 2, 15 (2005).

3. G.R. Saad, R.E. Morsi, S.Z. Mohammady, M.Z. Elsabee, J. Polym. Res., 15, 115 (2008).

4. O. Atıc1-Galioglu, A. Akar, R. Rahimian, Turk. $J$. Chem., 25, 259 (2001).

5. H. Patel, D.A. Raval, D. Madamwar, S.R. Patel, Die Angewandte Makromol. Chem., 263, 25 (1998).

6. H.Y. Liu, K. Cao, Z. Li, B.G. Yao, G.H. Hu, J. Appl. Polym. Sci., 104, 2418 (2007).

7. B.L. William, R. David, Kryscio1, V.S. Brandon, A.P. Nicholas, Annu. Rev. Chem. Biomol. Eng., 1, 149 (2010).

8. H. Ringsdorf, J. Polymer. Sci., 51, 135 (1975).

9. R. Duncan, Res. Foc. Rev., 2, 441 (1999).

10. K. Hoste, K.D. Winne, E. Schacht, Int. J. Pharmaceut., 277, 119 (2004).

11. K. Greish, T. Sawa, J. Fang, T. Akaika, H. Maeda, J. Cont. Rel., 97, 219 (2004). 
G. Karakus et al.: Design, synthesis, structural characterization and cell cytotoxicity of a new derivative ...

12. H. Maeda, M. Ueda, T. Morinaga, T. Matsumoto, $J$. Med. Chem., 28, 455 (1985).

13. A. Kobayashi, T. Oda, H. Maeda, J. Bioact. Compat. Pol., 3, 319 (1988).

14. N. Ohtsuka, T. Konno, Y. Myauchi, H. Meada, Cancer, 59, 1560 (1987).

15. H. Maeda, T. Matsumoto, T. Konno, K. Iwai, M. Ueda, J. Protein Chem., 3, 181 (1984).

16. K. Greish, J. Fang, T. Inutsuka, A. Nagamitsu, H. Maeda, Clin. Pharmacokinet., 42, 1089 (2003).

17. H. Maeda, Adv. Drug Deliv. Rev., 6, 181 (1991).

18. C. Mènez, M. Buyse, M. Besnard, R. Farinotti, P.M. Loiseau, G. Barratt, Antimicrob. Agents, 50, 3793 (2006).

19. M. Bruch, D. Mäder, F. Bauers, T. Loontjens, R. Mülhaupht, J. Polym. Sci. Pol. Chem., 38, 1222 (2000).

20. G. Karakus, H.B. Zengin, Z. Akin Polat, A.F. Yenidunya, S. Aydin, Polym. Bull., 70, 1591 (2013).

21. V. Nguyen, W. Yoshida, Y. Cohen, J. Appl. Polym. Sci., 87, 300 (2003).

22. D. Fles, R. Vukovic, A.E. Kuzmic, G. Bogdanic, V. Pilizota, D. Karlovic, K. Markus, K. Wolsperger, D. Vikic-Topic, Croat. Chem. Acta, 76, 69 (2003).

23. G. Karakus, Z. Akin Polat, A. Sahin Yaglioglu, M. Karahan, A.F. Yenidunya, J. Biomat. Sci-Polym., E. 24, 1260 (2013).

24. E. Chernikova, P. Terpugova, C. Bui, B. Charleux, Polym., 44, 4101 (2003).

25. Y. Li, S. Richard-Turner, Eur. Polym. J., 46, 821 (2010)

26. C.M. Xiao, J. Tan, G.N. Xue, Express. Polym. Lett., 4, 9 (2010).

27. G.C. Chitanu, I. Popescu, A. Carpov, Rev. Roum. Chim., 51, 923 (2006).

28. M.A. Krayukhina, S.A. Kozybakova, N.A. Samoilava, V.G. Babak, S.Z. Karaeva, I.A. Yamskov, Russ. J. Appl. Chem., 80, 1145 (2007).

29. Z. Qiao, Y. Xie, M. Chen, J. Xu, Y. Zhu, Y. Qian, Chem. Phys. Lett., 321, 504 (2000).

30. V. Sunel, M. Popa, A.D. Stoican, A.A. Popa, C. Uglea, Mater. Plast., 45, 149 (2008).

31. Z.M.O. Rzayev, Int. Rev. Chem. Eng., 3, 153 (2011)

32. J. Pal, H. Singh, A.K. Ghosh, J. Appl. Polym. Sci., 92, 102 (2004).

33. J.H. Jeong, Y.S. Byoun, S.B. Ko, Y.S. Lee, J. Ind. Eng. Chem., 7, 310 (2001).

34. L. Xiao, H. Shimotani, M. L J. Ozawa, N. Dragoe, K. Saigo, K. Kitazawa, J. Polym. Sci. Pol. Chem., 37, 3632 (1999).
35. G. Karakus, Z. Akin Polat, A.F. Yenidunya, H.B. Zengin, C.B. Karakus, Polym. Int., 62, 492 (2013).

36. H. Kaplan Can, A.L. Doğan, Z.M.O. Rzaev, A.H. Uner, A. Güner, J. Appl. Polym. Sci., 96, 2352 (2005).

37. R.L. Frost, Y. Xi, R. Scholz, M.B. Fernanda, Spectrochim. Acta. A103, 143 (2013).

38. R.L. Frost, Y. Xi, R. Scholz, M.B. Fernanda, A.D.M. Luiz Filho, Spectrochim. Acta, A104, 250 (2013).

39. R.L. Frost, A. Lopez, Y. Xi, A. Granja, R. Scholz, R.M.F. Lima, Spectrochim. Acta, A114, 309 (2013).

40. R.L. Frost, Y. Xi, M. Beganovic, F.M. Belotti, R. Scholz, Spectrochim. Acta, A107, 241 (2013).

41. R.L. Frost, Y. Xi, R. Scholz, Spectrochim. Acta, A108, 244 (2013).

42. R.L. Frost, Y. Xi, R. Scholz, F.M. Belotti, Spectrochim. Acta, A105, 359 (2013).

43. R.L. Frost, Y. Xi, R. Scholz, F.M. Belotti, M. Beganovic, Spectrochim. Acta, A110, 7 (2013).

44. R.L. Frost, R. Scholz, A. Lòpez, Y. Xi, Spectrochim. Acta, Part A: Molecular and Biomolecular Spectroscopy 124, 243 (2014).

45. S. Dos, W. Khan, S. Mohsin, N. Kumar, Polym. Adv. Technol., 22, 172 (2011).

46. S. Hwang, C.H. Lee, I.S. Ahn, J. Ind. Eng. Chem., 14, 487 (2008).

47. E. Lee, B.H. Moon, Y. Park, S. Hong, S. Lee, Y. Lee, Y. Lim, Bull. Korean Chem. Soc., 29, 507 (2008).

48. D. Jacquemin, E.A. Perpete, I. Ciofini, J. Chem. Theory Comput., 6, 2071 (2010).

49. K.J. Yoon, J.H. Woo, Y.S. Seo, Fiber Polym., 4, 182 (2003).

50. G. Nemtoi, C. Beldie, C. Tircolea, I. Popa, I. Cretescu, I. Humelnicu, D. Humelnicu, Eur. Polym., J., 37, 729 (2001)

51. H.E. Gottlieb, V. Kotlyar, A. Nudelman, J. Org. Chem., 62, 7512 (1997).

52. B. Basnar, M. Litschauer, S. Abermann, E. Bertagnolli, G. Strasser, M-A. Neouze, Electronic Supplementary Information. Layer-by-layer assembly of titania nanoparticles based ionic networks, Chemical Communications, 47, 361 (2011).

53. H. Kaur, K. Seifert, G.E. Hawkes, G.S. Coumbarides, J. Alvar, S.L. Croft, Am. J. Trop. Med. Hyg., 92 (Suppl. 6), 31 (2015). 